\title{
La fotógrafa Denise Bellon: surrealismo, documentalismo y fotografía humanista
}

\author{
Nekane Parejo \\ Universidad de Málaga
}

RESUMEN:

Entre 1920 y 1940 se desarrolla en Francia un movimiento fotográfico denominado Nouvelle Vision que acoge a un grupo de fotógrafas profesionales de este medio, entre ellas Denise Bellon. Las imágenes de esta autora, estrechamente vinculadas con los artistas de vanguardia, nos servirán para articular conexiones con aspectos relacionados con tres corrientes fotográficas patentes en su trayectoria: el surrealismo, la fotografía humanista y el documentalismo. Para lograr este propósito nos aproximaremos, por un lado, a los rasgos específicos de cada una de estas tendencias fotográficas y por otro, a la obra de Denise Bellon a través del ensayo fílmico Le Souvenir d'un avenir (Recuerdos del porvenir, 2001) donde Yannick Bellon, su hija y el cineasta Chris Marker orquestan una narración cronológica, en la que la imagen fija adquiere status de protagonista absoluta basándose en 25000 negativos registrados entre 1937 y 1956.

PALABRAS CLAVE:

Fotografía, Denise Bellon, Chris Marker, surrealismo, documentalismo.

\section{ABSTRACT:}

A photographic movement known as Nouvelle Vision that includes a group of professional photographers of this medium, including Denise Bellon, takes place in France between 1920 and 1940. The images of this author, closely associated with the avant-garde artists, will serve us to articulate connections with three photographic trends patents in its career: surrealism, humanistic and documentary photography. To achieve this purpose us approximations, on the one hand, to the specific features of these photographic trends and on the other hand, to the work of Denise Bellon through the film essay Le Souvenir d'un l'avenir (Memories of the Future, 2001) where Yannick Bellon, his daughter and the filmmaker Chris Marker orchestrate a chronological narrative, in which the fixed image acquired status of absolute protagonist based on 25000 negatives between 1937 and 1956.

\section{KEYWORDS:}

Photography, Denise Bellon, Chris Marker, surrealism, documentary. 


\section{Introducción}

En Francia entre las décadas de 1920 y 1940 se produce un incremento del número de fotógrafas; profesionales que se agrupan entorno al movimiento de la Nouvelle Vision y que desarrollan una actividad que tiene como lugar común la exploración del medio a través de sus imágenes. A esta situación contribuyeron dos condicionantes: los progresos técnicos y las escasas necesidades que esta práctica requería. El primer factor está directamente vinculado con la comercialización en 1925 de, las hoy ya clásicas, Rolleiflex y la Leica. Ambas cámaras contaban con una ventaja con respecto a sus predecesoras, ya que podían prescindir del trípode y con ello se permitía una movilidad mayor lo que las convertía en cámaras muy indicadas para la fotografía en exteriores. En segundo lugar, estamos ante unas máquinas en las que la prioridad se encaminaba hacia un fácil manejo. A propósito del medio fotográfico y sus exigencias, la crítica y asesora de arte Victoria Combalía indica que "era una disciplina que se puso de moda y que ofrecía la ventaja de su utillaje ligero, una mera cámara y a veces ni siquiera era necesario un estudio, pues revelaban en estudios de otros compañeros o eran asistentas de otros fotógrafos" (2006) ${ }^{1}$.

Nos estamos refiriendo a un grupo de fotógrafas compuesto por una veintena de autoras que, a diferencia de muchas de sus antecesoras $^{2}$, no pueden calificarse de aficionadas o de meras prolongaciones de sus maridos a los que ayudan en el laboratorio fotográfico como medio de entretenimiento. Se trata de auténticas expertas que, paradójicamente no pueden ejercer aún el derecho al voto ${ }^{3}$ y que retratan, entre otros motivos, a esa nueva mujer. De nuevo de acuerdo con Victoria Combalía:

\footnotetext{
COMBALIA, Victoria (2006), "Las fotógrafas pioneras de la vanguardia francesa se instalan en Barcelona" [Artículo en línea]. [acceso 29 setiembre 2014] Disponible en http://www.elmundo.es/elmundo/2006/05/04/ cultura/1146769072.html

2 Mención a parte requieren firmas como Margaret Bourke-White o Berenice Abott, entre otras, que ya habían demostrado sobradamente su valía a finales de los años 20. Para ampliar la información sobre los avances tecnológicos de esta décadas consúltese PAREJO, Nekane "Historias de fotógrafas", en Aula de Formación Abierta, 2007-08, Vicerrectorado de Servicios a la comunidad universitaria, Málaga, 2008, pp. 773-85.

3 Recuérdese que hasta 1944 no se estableció el sufragio universal en Francia.
}

Es el modelo de mujer moderna e independiente, que se gana la vida con su cámara, que se hace evidente en dos autorretratos: el de Germaine Krull con un cigarro encendido y rostro oculto tras su Agfa Ikarette y el de Ilse Bing con su Leica, verdaderos iconos de la profesionalización de estas fotógrafas 4 .

Algunas tan reconocidas como Dora Maar, Claude Cahun, Gisele Freund, Lee Miller o Lisette Model. Entre estas fotógrafas se encuentra Denise Bellon en realidad llamada Denise Hulmann ${ }^{5}$, objeto de estudio de este texto, una mujer "que supo sostener las miradas de los otros, fueran sujetos célebres o desconocidos, una mirada femenina capaz de devolver la belleza a los cuerpos y los ojos (a veces tristes), como los de las prostitutas tunecinas" ${ }^{\text {. }}$

\section{Propósito, estudio del arte y metodología}

Además de pertenecer a la Nouvelle Vision y encontrarse estrechamente vinculada con los artistas de vanguardia, en la obra de esta autora, confluyen tres recorridos fotográficos patentes en su trayectoria: el surrealismo, la fotografía humanista y el documentalismo. Nuestro objetivo, no es otro que atisbar en sus creaciones la aportaciones de cada una de estas tendencias. Para conseguirlo nos aproximaremos, por un lado, a las características específicas de cada una de estas corrientes fotográficas y, por otro, a su obra a través del ensayo fílmico Le Souvenir d'un avenir (Recuerdos del porvenir, 2001). Se trata de una película dirigida por el cineasta Chris Marker y su hija, Yannick Bellon, donde la imagen fija adquiere estatus de protagonista absoluta en una narración cronológica a partir de 25000 negativos registrados entre 1937 y 1956.

4 BOSCO, R., "Las grandes fotógrafas de la vanguardia protagonizan una exposición en la galería Barbié", en El País, 7 mayo 2006, p.34.

5 Este cambio de nombre era muy habitual. Es el caso del exiliado húngaro, André Friedman y de su alter ego el fotógrafo, Robert Capa o cuando encontramos en la misma persona a David Szymin que responde a un refugiado polaco, a un David Seymour con nacionalidad americana, y a un foto-reportero que firma sus trabajos con el nombre de Chim.

6 ORTEGA GÁLVEZ, María Luisa, "Souvenir d'un avenir (Recuerdos del porvenir) (Chris Marker y Yannick Bellon”, 2001), en Solos ante la cámara. Biopics de fotógrafos y cineastas, Luces de Galibó, Barcelona, 2011, pp.27-28. 
Serán precisamente esos 25000 negativos los que conformen el universo de esta investigación que se asienta en el análisis de contenido en su versión más cualitativa. A partir de ahí la muestra estará constituida por todas aquellas fotografías que forman parte del metraje en cuestión y que serán objeto de estudio a través de tres categorías que se corresponden con las tres corrientes mencionadas y en las que la obra de Denise Bellon es susceptible de ser integrada.

Esta muestra se justifica debido a que Recuerdos del porvenir es una película fotográfica, como decíamos, basada en los archivos de Denise Bellon. Los cineastas convierten estas imágenes fijas en "el instrumento para reinventar dos de las constantes de la obra de Marker: el retrato y los viajes en el tiempo histórico densificados por la reflexión política"'.

Una película donde cobra fuerza el montaje de una sucesión de imágenes de la autora combinándose mediante fundidos y sobreimpresiones. Además, durante todo el metraje sobresale una voz narradora, la de Pierre Arditi, encargado no sólo de describir las fotografías, sino del hilvanarlas entre sí y convertirlas en una historia, que fragmentariamente no existió: "Nada de todo esto fue, por mucho tiempo, verdad. Pero lo es en el tiempo del film"8.

$\mathrm{Su}$ eficacia radica en la fuerza de evocación de una instantánea que destapa la caja de Pandora de los recuerdos, cumpliéndose de este modo el objetivo de sus directores: "intentar analizar el modo en que percibimos una foto que ya es antigua (...) La foto que ya tiene unos años muestra, entre ella y nosotros, entre la imagen y el presente, una duración implícita" Así, la del maquis fusil al hombro y de perfil o la de los republicanos tras una trinchera de nieve en los Pirineos de 1944, cuando éstos intentaron con un estrepitoso fracaso conquistar la España franquista, nos retrotrae a la Guerra
Civil, pero también al final de la dictadura y a la transición.

Otro aspecto que pone en valor Recuerdos del porvenir como muestra es la inclusión de primicias como las fotografías que acabamos de mencionar, imágenes olvidadas por los libros de historia, y otras que parecen increíbles, pero que la cámara de Denise captó como prueba. Es el caso de Henri Langlois: “¿Quién es Henri Langlois? Un hombre que no se resigna a que las películas desaparezcan de quien se dice que las apila en su bañera. Uno se preguntaba si era una leyenda. Denise Bellon estaba allí para responder. La única imagen de la fabulosa bañera, cuna de todas la cinematecas".

El punto de partida para determinar el estado de la cuestión será una aproximación a estas tendencias fotográficas. Para abordar el humanismo nos centraremos en las aportaciones de Pierre $\mathrm{Amar}^{10}$ que destaca los rasgos que definieron a los humanistas franceses y a sus imágenes. Además, este autor se hace eco de las consideraciones de Bertran Éveno cuando señala a la persona como epicentro de las obras de estos artistas y establece dos aspectos prioritarios en relación a esta: lo cotidiano y lo político.

En lo que a la fotografía documental se refiere recuperamos el capítulo de libro "Fotografía y cine documental: dos territorios con la realidad con frontera" de Rafael Tranche ${ }^{11}$ para delimitar la controvertida fecha de aparición de este movimiento. Por otra parte también nos serán de utilidad las líneas establecidas por la agencia Alliance Photo y las consideraciones de Rafael Olmeda ${ }^{12}$ en cuanto al desempeño de este género fotográfico. Finalmente para completar el desarrollo histórico se recurrirá a las definiciones a cerca de la figura del fotógrafo documental expresadas en el artículo "De la foto documental al documento digital"13.
ORTEGA GÁLVEZ, María Luisa, "El gran montador. Fotografía y documental en la obra de Chris Marker", en R. Tranche (Ed.) De la foto al fotograma. Fotografía y cine documental: dos miradas sobre la realidad, Ocho y medio, Madrid, 2003, p.220.

8 LEDO ANDIÓN, Margarita, Cine de fotógrafos, Gustavo Gili, Barcelona, 2005, p.222.

9 BELLON, Yannick, "Ensayo filmado sobre el arte de la fotografía a partir de los archivos de Denise Bellon", en Chris Marker con Yannick Bellon, Fran Benavente, Gonzalo de Lucas, Isaki Lacuesta, Sergi Dies y Catherine y Andrew Brighton, Intermedio, Barcelona, 2007, p.12.
10 AMAR, Jean Pierre, El fotoperiodismo, La Marca, Buenos Aires, 2005.

11 TRANCHE, Rafael, "Fotografía y cine documental: dos territorios con la realidad con frontera”, en R. Tranche (Ed.), De la foto al fotograma. Fotografía y cine documental: dos miradas sobre la realidad, Ocho y medio, Madrid, 2003.

12 OLMEDA, Fernando, Gerda Taro. Fotografía de guerra. El fotoperiodismo como testigo de la historia, Mondadori, Barcelona, 2007.

13 PAREJO, Nekane, "De la foto documental al documento digital”, Zer, 25, Bilbao, 2008. 
Las apreciaciones de Estrella de Diego ${ }^{14}$, que vinculan la fotografía surrealista con las imágenes documentales, se convertirán en el nexo de unión que nos permitirá transitar por los orígenes del surrealismo. Para esta última cuestión se acudirá a Christine De Naeyer ${ }^{15}$. Además, se tendrán presentes las contribuciones de José Gómez Isla ${ }^{16}$ en cuanto a la polémica en torno al fotógrafo Eugene Atget como participe de este movimiento.

Respecto a Denise Bellon y Chris Marker resultan esclarecedoras las aportaciones, tanto respecto a su biografía como a su obra, de $\mathrm{M}^{\mathrm{a}}$ Luisa Ortega Gálvez que en Souvenir d'un avenir (Recuerdos del porvenir) (Chris Marker y Yannick Bellon", 2001) se adentra en los entresijos colaborativos de estos dos creadores cinematográficos.

\section{Denise Bellon y la foto humanista}

Esta tendencia, también denominada realismo poético, sitúa a la persona y su hábitat en el punto de mira del objetivo. A finales de los años 30 y con más profusión en la postguerra el sujeto y su entorno son los protagonistas de unas tomas donde se pretende redescubrir la figura humana y se prioriza el disparo fotográfico en exteriores y en directo. Instantáneas en las que el testimonio documental y el idealismo comparten unos encuadres informales, mordaces y sensibles. Lo cotidiano y lo social se evidencian en retratos de personajes entrañables. Serán los franceses Willy Ronis, Édouard Boubat, Robert Doisneau, Henri Cartier-Bresson, etc. los autores más representativos de esta tendencia en la que "había bastantes mujeres, más de las que solía ser habitual" ${ }^{17}$. Una presencia que se justifica por una temática próxima, el quehacer diario. Entre ellas, Denise Bellon que en pala-

14 DE DIEGO, Estrella, "Los cuerpos perdidos", en Los cuerpos perdidos. Fotografía y surrealismo. Fundación La Caixa, Barcelona, 1995.

15 DE NAEYER, Ch., "Subversión de las imágenes. Cómo Paul Nougé inviste lo cotidiano”, en Papel Alpha, 2, Salamanca, 1996.

16 GÓMEZ ISLA, José, Fotografía de creación, Nerea, San Sebastián, 2005.

17 Según el catálogo La Photograpie Humaniste. Histoire d'un mouvement, 1930-1960, había 14 mujeres entre los 56 fotógrafos. Véase GARCÍA FELGUERA, M. S.,"De la posguerra a los años 60", en Souguez, M. L. Souguez (Ed.), Historia general de la fotografía, Cátedra, Madrid, 2007, pp.493-536. bras de Eric Le Roy ${ }^{18}$ cuenta con una obra que es: "Témoignage humain, social, culturel. L'être humain será toujours, jusqu'à la fin de sa vie au centre de son regard" 19 .

De acuerdo con Jean-Pierre Amar: Estos humanistas franceses compusieron para nosotros una imagen de Francia que forma parte del patrimonio cultural (...) Algunas de sus obras tienen hoy un valor arquetípico ya que son representativas de hechos sociales. Resulta especialmente el caso del Front Populaire y de la liberación de París pero también de los primeros feriados pagos de pequeños oficios (viñeteros, albañiles, vidrieros, afiladores), bailes populares o de la vida en los barrios. Estas imágenes están por supuesto cargadas de gran nostalgia, la de los viejos buenos tiempos ${ }^{20}$.

De este modo encontramos fotografías de Denise Bellon con hombres asfaltando una carretera a mano o caballos en mitad de una calle atados a una puerta. En la película de Chris Marker, Recuerdos del porvenir, el narrador lo describe a la perfección: "París cambia despacio. Los obreros de la calle parecen campesinos. Asfaltan como vendimiadores. Hay caballos de tiro en las puertas de las Tullerías".

En la misma línea, donde prevalecen los personajes singulares y callejeros, se localiza una toma de un señor vendiendo en un puesto en la vía pública o unos músicos tocando el saxofón y el clarinete. Posteriormente, y casi al unísono de los preparativos de la II Guerra Mundial, Denise Bellon retratará esas profesiones $^{21}$ a las que se refiere Amar y por sus imágenes desfilarán zapateros, costureras, afiladores... oficios de otra época que se recuperan

18 Fue el director de producción de la película y el actual presidente de la Federación Internacional de Archivos de Films (2011-).

19 LE ROY, Éric, “A propos de Denise Bellon”, en Denise Bellon. Le regard vagabond. Disponible en línea: http:// www.denise-bellon.fr/ [Consulta 3/2/2017]. En este sentido es imprescindible la monografía: LE ROY, Éric, Denise Bellon, Éditions de la Martinière, Paris, 2004.

20 AMAR, Jean Pierre, El fotoperiodismo, opus cit., p. 68.

$21 \quad$ En este sentido se debe recordar que entre 1898 y 1927 Eugène Atget retrata la cotidianidad parisina de principios de siglo y aunque dentro de su colección de más de 4000 imágenes prevalecen aquellas que documentan la renovación urbana, también se hace eco de los oficios menores, que consideraba en vías de desaparición. Es el caso de tomas como Alquiler de barquitos, Jardin du Luxembourg, 1899 o Cantante callejera y organillero, 1898, una pareja de músicos en la calle con obvias concomitancias con las de Denise Bellon. 
momentáneamente. Prueba de ello es que será esta autora la que inmortalice el último rebaño de bueyes cruzando Lyon.

En este sentido Bertran Éveno señala cómo el motivo principal, la persona, se diversifica en su tratamiento en dos materias: "Al colocar en el centro de todo a la figura humana, esta fotografía la considera en toda su unidad (y) oscila entre dos polos: por un lado la poesía de la vida cotidiana, por otro la constatación social más o menos orientada a fines de combate político" 22 . En definitiva, este autor fusiona, en su interpretación acerca de la persona como motivo de interés predominante, dos aspectos: lo político y lo cotidiano.

En la obra de la fotógrafa francesa se combinan con habilidad estos dos extremos. En ocasiones en la misma toma y en otras separadamente como las que se han expuesto o las pertenecientes a la primavera en un París de preguerra. Tanto las primeras como las segundas se enmarcan en el ámbito de lo rutinario, en un estadio que precede al combate. Así vemos instantáneas que rezuman calma y sosiego como la de unas mujeres leyendo en bancos, estudiantes que pasean por los jardines de la Sorbona, terrazas de bares muy concurridos... En definitiva, conversación, lectura y champagne en un París cómodo, en el que el tiempo de impasse que precede al conflicto armado, y a tenor de estas fotografías, parece disfrutarse en todas sus dimensiones. Chris Marker también muestra esta situación cuando ante una imagen de un señor que desde su automóvil saluda a una chica y parece invitarla a pasear, comenta: "Hay conductores que ligan en Citröen, pero no dicen Citröen, sino Citrón”.

A medio camino entre los dos polos establecidos por Éveno, emergen unas imágenes de la Exposición Universal de 1937 en París. Instantáneas, que parecen ser premonitorias del acontecer de una II Guerra Mundial muy cercana, y en las que los pabellones de dos naciones en un futuro enemigas se encaran. Tomas diversas donde un hombre en silla de ruedas espera bajo el rótulo del pabellón de Alemania u otra en la que varias personas permanecen sentadas bajo la hoz y el martillo, símbolos inconfundibles del régimen de la antigua URSS. Al respecto, la película asemeja estas construcciones a unas imitaciones que una vez terminada la Exposi-

22 Citado por AMAR, Jean Pierre, El fotoperiodismo, opus cit., p. 67. ción y destruidas son las que despejarán el camino para dejar paso a los señores de la guerra.

Denise Bellon aborda el segundo aspecto, la constatación social encaminada hacia objetivos políticos, en tres tempos distintos que se entremezclan en sus fotografías. Así, pasado, presente y futuro emergen en los retratos del poeta francés Joë Bousquet ${ }^{23}$, herido en la I Guerra Mundial y postrado en la cama desde 1918 por una bala alojada en la columna. Retratos que dan sobradas muestras de su situación, pero con naturalidad y sencillez. Desde la perspectiva de una amiga, que es en lo que se convirtió Denise Bellon y a la que un poeta agradecido escribe: "Muestran que vivo en la sombra y que vuestras manos saben traerme la luz". Retratos que advierten de las atrocidades de un nuevo enfrentamiento.

Las fotografías de los preparativos inmediatamente anteriores a la II Guerra Mundial también remiten a un pasado, en el que los atuendos de los soldados de este conflicto se confunden con los de los combatientes de la I Guerra Mundial. Estas imágenes de soldados, que parecen de otra época, junto con otras de carácter más comprometido y visionario que anuncian las precariedades que sufrirá la población francesa, constatan el carácter social de este movimiento fotográfico. Tomas de unas alumnas en clase con una manta por encima o todos los miembros de una familia apilados en una misma estancia pronostican un futuro incierto, plagado de privaciones.

Además, la obra de Denise Bellon da cuenta de las que podemos considerar primeras imágenes de la II Guerra Mundial. Se trata de unas maniobras de verano anteriores a la invasión de Polonia en las que soldados en bicicleta ejecutan las primeras movilizaciones que tienen lugar en Finlandia. Nuevamente la acción es sustituida por la placidez de un ejército, simplemente, entrenándose.

A lo expuesto con respecto a la foto humanista se debe añadir una propuesta de contenido que exime a la figura humana de su protagonismo absoluto. Se trata de los puentes y la bruma como motivo de interés y que también tienen cabida en las imágenes de Denise Bellon. El Pont Neuf, el de Bercy, entre otros, son re-

\footnotetext{
23 Bousquet resultó herido a los 21 años por las tropas alemanas. La falta de movilidad hizo que permaneciera recluido en una habitación de su casa con las contraventanas cerradas y dedicado a su oficio, la escritura.
} 
gistrados desde una perspectiva descriptiva que dará paso a otra más imprecisa en la que la niebla y la noche no permiten reconocer la figura de un hombre apoyado en uno de sus laterales.

\section{Denise Bellon y el fotorreportaje documental}

Estrechamente vinculada con la fotografía humanista se posiciona la noción de lo documental. Estamos ante un término que no fue empleado hasta 1930. No obstante, una clasificación tradicional de la fotografía delimita a los autores que apuestan por el documento puro $^{24}$, sin alteraciones, y los que defienden la fotografía como recurso expresivo. Los historiadores están de acuerdo en que los orígenes de este vocablo deben situarse en la Europa de 1926 cuando John Grierson definió la película Moana de Robert Flaherty. Fotográficamente, y siguiendo a Rafael Tranche, también se sitúa "a finales de los años veinte aplicado a la fotografía social que practican Walter Evans, Dorotea Lange o Arthur Rothstein sobre todo a partir de la Depresión"25.

En cualquier caso, si los primeros documentalistas seguían escrupulosamente unos preceptos basados en lo que se denominó "el registro puro", en los años 30 se vislumbra una evolución. Ese fotógrafo cuya máxima era estar pero no intervenir, se transforma en un testigo espontáneo, alguien que debe fijar su atención en lo que le rodea para visualizar sus posibles concordancias sin variar su contexto. Será entonces, a partir de los años 30 y hasta la posguerra en los 50 cuando los fotógrafos se lancen a recorrer el mundo porque "el fotógrafo documental debe estar ahí y saber encontrar y registrar con su cámara, sin elaborar y manipular la imagen"26.

Y ahí está Denise Bellon transitando por África y Asia, por el imperio francés; ella retrató las dos caras del colonialismo en setiembre de 1939. En sus tomas se plasma el aprendizaje de la lectura y la escritura por parte de los niños del país, pero también imágenes de colonos re-

$24 \quad$ La fotografía documental cuenta entre sus antecesores con las imágenes de denuncia social elaboradas por Jacobs Riis y Lewis Hine a finales del siglo XIX.

25 TRANCHE, Rafael, "Fotografía y cine documental: dos territorios con la realidad con frontera”, opus cit, p. 15.

26 PAREJO, Nekane, "De la foto documental al documento digital”, opus cit., pp. 184. visando dentaduras adultas como si de caballos se tratara. Como el disidente surrealista Michel Leiris, captó la belleza para después decantarse por lo cotidiano que marca las distancias entre lo civilizado y lo salvaje, entre lo habitual y lo exótico. A propósito de esta situación y de cómo es percibida por el escritor, Estrella de Diego señala:

Ese juego constante entre lo de aquí y lo de allí, entre París y África, será precisamente lo que plantea la tensión en unas páginas que en apariencia son sólo una descripción cuidadosa de lo que va acaeciendo durante la misión ${ }^{27}$.

Lo mismo ocurre con las imágenes de la fotógrafa francesa que según manifiesta Marker: "un día fotografía una boda judía en Yerba. Otro...una boda gitana en París".

En pos de este fotorreportaje documental Denise Bellon se adentró en el acontecer de lo diferente hasta llegar a las minas de diamantes, para luego seguir su camino hacia el norte, hacia el Magreb. Un protectorado del que supo extraer su esencia diez años después de finalizada la guerra del Rif. Las fotos emanan la tranquilidad que registra esta región, y marineros con chicas sonrientes se alternan con panorámicas de su paisaje. Además, Denise, al modo de Cartier Bresson, retratará con decisión y ternura a las prostitutas, en este caso, del barrio reservado de Túnez, aportando una perspectiva femenina.

Éstas y otras aportaciones entorno al fotorreportaje serán recogidas por la agencia Alliance-Photo creada en 1934 y que tuvo a los mejores fotógrafos del momento. Surgió de la unión entre María Eisner- fotógrafa alemana con amplia experiencia en el campo de las agencias de la información- y el grupo de fotógrafos del estudio Zuber (Robert Capa, Paul Boucher... y Denise Bellon). Las fotografías de Alliance se publicaron en Art et Médecine, Arts et Métiers, Graphique, Paris-Magazine y V $u^{28}$.

Una agencia cuya intención fue ir descubriendo el mundo mediante la fotografía, bajo el lema que se recoge en Recuerdos del porvenir: "Ser fotógrafo no sólo es mirar, es sostener la mirada de los otros". En este sentido, Fernando Olmeda señala que: "se distinguen por su nueva forma de mirar: fascinados

\footnotetext{
${ }^{27}$ DE DIEGO, Estrella, Los cuerpos perdidos. Fotografía y surrealismo, opus cit., p. 13.

28 PÉREZ GALLARDO, Helena, "El reportaje gráfico", en M.L. Souguez (Ed.), Historia general de la fotografía, Cátedra, Madrid, 2007, pp. 442.
} 
por lo raro, entusiasmados por la técnica y la arquitectura modernas, crean imágenes que muestran la realidad desde una perspectiva poco habitual" 29 .

Cuando termina su andadura en Alliance-Photo, Denise Bellon abandona la travesía de los grandes reportajes para instalarse en lo que podíamos denominar los temas pequeños, una foto familiar y doméstica.

\section{Denise Bellon y el surrealismo}

La fotografía documental y la surrealista están más relacionadas de lo que en un principio puede parecer. El surrealismo inventado por Guillame Apollinaire, surge como término del encuentro entre el teórico del grupo surrealista en Bruselas y más tarde fotógrafo, Paul Nougé y el pintor René Magritte que se conocen en 1924 y juntos conciben una relación esencial con el mundo que bautizan, por no encontrar nada mejor, surrealismo" ${ }^{30}$. En palabras de Breton se trata de "tomar conciencia cada vez más clara y al mismo tiempo crecientemente apasionada del mundo sensible" ${ }^{31}$. Esto aplicado a la imagen fotográfica plantea dos alternativas: la que se fundamenta en las transformaciones mediante el uso de una serie de técnicas como la solarización, el fotograma, el collage, etc. y la que se fundamenta en una exploración del mundo visual. Y va a ser esta última la que entronque con lo documental. Planteamientos como el París de Eugene Atget, largamente aplaudido por los surrealistas, y que recorren los lugares más recónditos de esta ciudad, son una muestra reconocida de esta exploración y búsqueda pretendida por la fotografía surrealista. Sin embargo, y aquí está la paradoja, este autor no se sentía participe de los principios de esta corriente: "cuando Man Ray o Breton quisieron vincular a Atget con los postulados surrealistas, se encontraron con la afirmación autoexcluyente de éste: "Lo único que hago son documentos" ${ }^{32}$.

29 OLMEDA, Fernando, Gerda Taro. Fotografía de guerra, opus cit., p. 87.

30 DE NAEYER, Ch., "Subversión de las imágenes. Cómo Paul Nougé inviste lo cotidiano”, opus cit., p.55.

31 Citado por MADEAU, M., Historia del Surrealismo, Altamira, Buenos Aires, 1993, p. 84.

32 GÓMEZ ISLA, José, Fotografía de creación, opus cit. p. 12.
El tiempo ha otorgado la razón a Atget y a los surrealistas, encontrando un consenso en sus posturas. Acuerdo que Estrella de Diego matiza con exactitud: "Las fotografías de los surrealistas son documentales en tanto documentos de una incertidumbre" ${ }^{33}$.

Una incertidumbre de la que la película da cuenta desde la exposición surrealista de 1938 hasta la de 1947 a través de la obra de Denise Bellon. El metraje comienza con la imagen de un maniquí. No se debe olvidar que el cuerpo femenino es reinventado por los surrealistas y transmutado en un maniquí aderezado a su gusto. Por tanto, este elemento se convierte en uno de los motivos fetiche de esta tendencia. En la película que nos ocupa estará acompañado de una voz over que relata la llegada de los visitantes al evento. Fotos fijas, cuyo contenido, vuelven a ser variaciones sobre el prototipico muñeco idolatrado por los surrealistas, que deja paso a la identificación por parte del narrador de su autora: "Hoy tenemos unas imágenes perfectas de este acontecimiento gracias a la mirada de una mujer. Denise Bellon captó el momento único".

La relación entre esta fotógrafa y el surrealismo se establece por partida doble. No sólo dispone de una serie de imágenes en las que se aprecia esta tendencia, sino que, a la par, retrata a sus amigos los surrealistas y su obra. Así el doble objetivo de su cámara recoge a Yves Tanguy pintando, la mirada de Marcel Duchamp, Dalí con un maniquí sin cabeza, Jacques Prévert leyendo... numerosas tomas del castillo del Cartero de Cheval, una bañera llena de latas de película apiladas de Langlois... Y sobre todo a su amigo Breton del que irán emergiendo diversos instantes capturados que evidencian complicidad. Prueba de este entendimiento es la dedicatoria del libro Les vases communicants, la primera que realiza.

En Recurdos del porvenir se sugiere, y esta sería la segunda vertiente, que "su amistad con los surrealistas había expuesto a Denise Bellon a una radiación secreta, que no influyó sólo en su mirada". Y que da lugar, aunque exigua, a una obra surrealista propia en la que fotografías de ojos, manos y cabezas, como si de muñecos para el aprendizaje de la anatomía se tratara, se suceden.

\footnotetext{
33 DE DIEGO, Estrella, Los cuerpos perdidos. Fotografía y surrealismo, opus cit., p. 20.
} 
Y finalmente, tras un periodo en el que la fotografía familiar invade sus encuadres, se reúne de nuevo con los surrealistas. Imágenes de sus dos hijas, mientras van creciendo, tomando el sol o bebiéndose un chocolate, su perro secándose, o pequeños detalles de la decoración de su casa, una monja junto a unas carpetas... se entremezclan con panorámicas paisajísticas o retratos de amigos. Retratos de amigos como cuando, por última vez, congrega a las afueras de París, en el desierto de Retz, al grupo surrealista, que posa con máscaras blancas.

\section{Conclusiones}

Tras este recorrido podemos afirmar que Denise Bellon se ajusta a la perfección al prototipo de fotógrafa, con el que comenzábamos este texto, al de una fotógrafa profesional que se integra en el movimiento de la Nouvelle Vision. Una fotógrafa que supo plasmar instantes cotidianos y únicos, desde una perspectiva documentalista y un espíritu humanista, con un toque de surrealismo propiciado por el círculo de amistades que marcan su obra.

Nos planteábamos al principio como propósito principal encontrar cuáles eran las concomitancias de su obra con cada uno de los movimientos a los que perteneció. Podríamos destacar que, del mismo modo que los fotógrafos humanistas, consiguió ubicar a la persona como el eje vertebrador sobre el que pivotan el resto de los motivos. Para lograrlo la situó en su hábitat más próximo y desde un punto de vista social dio cuenta de sus quehaceres habituales. Desde esta premisa se hizo eco de los personajes más singulares y con profesiones en proceso de extinción. Pero también de la cotidianidad del tempo que precede a un conflicto armado, la II Guerra Mundial, que se fusiona con imágenes de las secuelas del primer enfrentamiento internacional.

Desde una perspectiva documental cabría señalar el hecho de que Denise Bellon supo estar atenta para poder captar las conexiones espontáneas del entorno. Un entorno que ella misma configuró en su tránsito por África y Asia y que entronca con el de los más destacados fotorreporteros de la época, con los que también compartió agencia y las revistas más reputadas.

Finalmente el surrealismo cobra fuerza en sus tomas mediante una obra fotográfica propia que recoge los parámetros y contenidos más frecuentes de este movimiento, entre los que destaca la exploración y la búsqueda. Además, retrata a sus amigos surrealistas desde planteamientos puramente humanistas y documentales.

\section{FICHA TÉCNICA ${ }^{34}$}

Le Souvenir d'un avenir (Recuerdos del porvenir, 2001)

Francia. Blanco y negro. Betacam SP. 41 $\min$.

Un film de Yannick Bellon y Chris Marker.

Producción: Les Films de l'équinoxe/ARTE France, con el apoyo de PROCIREP y la participación de CNC y el Ministerio de Cultura.

Fotografías: Denise Bellon.

Narrador: Pierre Arditi.

Tejido sonoro: Michel Krasna.

Música de los créditos: Frederic Mompou.

Truca: Marchetti.

Post-producción: Jean-François Naudon.

Mezclas: Floren Lavallée.

Laboratorio: Centrimage.

Estudios de grabación: Aura fims/Diglson.

Dirección de producción: Éric Le Roy. 